\title{
Spatial Analysis of Salt Heterogeneity in a Central Californian Grape Field
}

\author{
Florence Cassel $^{1} \&$ Shankar Sharma ${ }^{2}$ \\ ${ }^{1}$ California State University, Fresno, USA \\ ${ }^{2}$ University of California, Merced, USA \\ Correspondence: Florence Cassel, Department of Plant Science, California State University Fresno, 2415 E. San \\ Ramon Avenue, M/S AS 72, Fresno, California 93740, USA. E-mail: fcasselss@csufresno.edu \\ Received: August 25, 2017 \\ Accepted: August 30, 2017 \\ Online Published: September 23, 2017 \\ doi:10.5539/enrr.v7n3p89 \\ URL: https://doi.org/10.5539/enrr.v7n3p89
}

\begin{abstract}
Grape is one of the major crops produced in California; however, moderate salt concentrations in the soil pore space can affect its growth. Therefore, it is important that the root zone salinity be rigorously monitored and maintained below the threshold limit for grape. Spatial analysis of salt heterogeneity can facilitate site-specific management for the crop. We conducted an electromagnetic salinity survey followed by semivariance modeling and kriging analyses in order to quantify the spatial variability and structure of salt distributions in a central Californian grape field. Soils in the study area had silty clayey texture and the salinity across the root zone remained largely elevated with random variations. Around 78 and $19 \%$ of the salinity values remained in the 3-4 and 4-4.5 $\mathrm{dS} \mathrm{m}^{-1}$ ranges, respectively. The 3.5-4 $\mathrm{dS} \mathrm{m}^{-1}$ level represented one of the most abundant concentrations across the areas of salt build up in the grape field. Based on our variogram and crossvalidation analyses, the Gaussian model fitted best to the salinity data $\left(\mathrm{r}^{2}=0.996, \mathrm{RSS}=0.0003\right)$. The salt heterogeneity was characterized by high structural variance $(99 \%)$ and low nugget effect $\left(C_{0}=0.014\right)$. The kriging analysis demonstrated a large spatial dependence of salinity that extended beyond a $1000 \mathrm{~m}$ radius. The isotropic nature of the spatial correlation structure produced an omnidirectional variogram. The overall salinity levels across the field surpassed the salt tolerance threshold for grape and the spatial analyses identified sensitive zones and their structures that require precise adaptive management.
\end{abstract}

Keywords: Grape, Salt, Heterogeneity, Semivariance, Kriging

\section{Introduction}

California is one of the most productive agricultural regions in the world growing over 250 crops, including grapes. The state produces around $6.7 \mathrm{Mt}$ of grapes including $4 \mathrm{Mt}$ of wine grape varieties that nearly contribute US $\$ 58$ billion to the economy annually (CDFA, 2017). In central California, grape is one of the major crops grown, supplying about three quarters of the state production. However, many irrigated lands within this area have been undergoing salinization that is subsequently affecting crop production (Cal EPA, 2006). Deteriorations of these lands are attributed to several factors including soil texture, inherent soil salinity, high evapotranspiration, and irrigation with saline water. Land degradation due to salt buildup has already affected many agricultural ecosystems around the globe (Metternicht \& Zinck, 2003; Martinez-Beltran \& Manzur, 2005).

The quality and composition of grapes are adversely impacted by salinity (Walker et al., 2014; Mirás-Avalos \& Intrigliolo, 2017). Grapevine growth is affected by the osmotic pressure resulting from the increase in salt concentrations in the soil pore space and subsequent ionic transport into the plant cells, where the nutrient levels surpass the beneficial threshold and cause toxicity. The detriment is further augmented under application of saline irrigation water.

Under degrading soil conditions, it is therefore necessary to determine the precise occurrence and the extent of salt accumulation in grape fields. Application of geospatial analysis of salt heterogeneity can facilitate site-specific identification of salinity build up zones that require adaptive management of the land and water resources in order to keep the salinity levels within the threshold limit tolerated by grape. Thus, the objectives of this study were to characterize soil salinity and quantify the spatial distribution and structure of salt heterogeneity in a central Californian grape field. Following a dual-dipole electromagnetic (EM) survey, we conducted stochastic 
computations, semivariance modeling and kriging analyses to estimate the spatial variability of salt distributions across the grape field. Similar EM surveys have been successfully applied to diverse environments including groundwater recharge (Cook et al., 1992), wetland (Paine et al., 2004), arctic Neolithic site (Viberga et al., 2013) and agricultural soil (Cassel, 2017). Our study offers uniquely integrated fundamental tools comprising electromagnetic, stochastic and geostatistical methods that can provide an insight for natural resource management for salt buildup in agro-ecological environments. Similar approach can be applied universally for a solution oriented agricultural research.

\section{Materials and Methods}

\subsection{Soil Survey and Analysis}

A dual-dipole EM survey was conducted in a 25-ha grape field of central California, where the soils belonged to the Lethent series characterized by clayey saline properties that became further affected by intensive irrigation and inadequate drainage (Cal EPA, 2006; USDA, 2006 \& 2014). The EM sensors (EM-38DD) were operated to measure soil electrical conductivity at a frequency of $14.6 \mathrm{kHz}$. The sensors consisted of two integrated units oriented in the horizontal and vertical positions to provide synchronized measurements over observation depths of 0.8 and $1.5 \mathrm{~m}$, respectively. The dual instrument was placed in a PVC carrier-sled attached approximately $3 \mathrm{~m}$ behind a tow-vehicle to avoid any signal interference due to metallic objects. A global positioning system was used with the EM instrument and the data were differentially corrected to sub-meter accuracy in order to obtain precise geographical coordinates of each measurement point. The EM readings and their corresponding locations were instantaneously recorded to an on-board computer through digital interfaces. The fundamentals of the EM technique were already discussed by Cassel et al. (2015), who demonstrated that the dual-dipole EM survey offered a rapid and effective tool for salinity assay in central California.

After completion of the EM survey, an optimal soil sampling plan with spatial representativeness of the entire survey area was generated based on Lesch et al. (2000) and ground-truth soil samples were collected at the planned locations across $0.9 \mathrm{~m}$ depth within 48 hours of the survey. Next, the soil samples were analyzed for electrical conductivity, volumetric moisture content and water saturation percentage following procedures described by Dane and Topp (2002) and Gavlak et al. (2003). Based on the EM survey results and the ground-truth soil data, salinity was estimated using stochastic analyses available in Lesch et al. (2000). The descriptive statistical evaluation of the data was completed following Lesch et al. (2000) and Robertson (2000).

\subsection{Geostatistical Analyses}

The spatial structure of the salinity data was determined through experimental variogram and cross-validation models using geostatistical methods (Robertson, 2000). The experimental variogram was obtained from statistical autocorrelation analyses and the semivariance $(\gamma(h))$ for the lag distance $(h)$ was defined as:

$$
\gamma(h)=[1 / 2 N(h)] \sum\left[\mathrm{z}_{i}-\mathrm{z}_{i+h}\right]^{2}
$$

Where, $\mathrm{z}_{i}=$ measured sample value at point $i ; \mathrm{z}_{i+h}=$ measured sample value at point $i+h ; i=1,2,3, \ldots ., N$; and $N(h)=$ total number of sample couples for the lag distance $h$. The $\gamma(h)$ was evaluated for all possible pairs of points within a $50 \mathrm{~m}$ class interval. Ordinary kriging was utilized to incorporate the spatial autocorrelations between surveyed points using a weighing factor to assign increased influence to the nearest data points. The Gaussian model best described the experimental semivariogram developed in our study based on autocorrelation distance between soil salinity measurements. The spatial structure of the Gaussian model was defined as:

$$
\gamma(h)_{\text {gaussian }}=C_{0}+C\left[1-\exp \left(-h^{2} / A_{0}^{2}\right)\right]
$$

Where, $C_{0}=$ nugget variance (y-intercept of the model); $C=$ structural variance; $C_{0}+C=$ sill (model asymptote); and $A_{0}=$ range (distance over which spatial dependence exists). Following the kriging stochastic analysis, the spatial maps of salinity distributions were generated using the GS+ program (Robertson, 2000).

\section{Results and Discussion}

Summary statistics of the analytical data are presented in Table 1 . The grape field exhibited electrical conductivity ranging from 1.6 to $5.7 \mathrm{dS} \mathrm{m}^{-1}$ with a moderate coefficient of variation $(\mathrm{CV})$ of $31 \%$. The salinity levels ranged from 2.8 to $4.8 \mathrm{dS} \mathrm{m}^{-1}$ and were characterized by $10 \% \mathrm{CV}$. The mean (M) values of conductivity and salinity were 3.6 and $3.7 \mathrm{dS} \mathrm{m}^{-1}$, respectively. There was a greater variability in salinity at the subsurface than in the surface soil. The salinity increased with depth and indicated downward salt movement. Soil saturation in the grape field ranged from 27 to $48 \%$ and maintained a $39 \%$ mean value with a moderately low variability at $16 \% \mathrm{CV}$. The soil water contents were near field capacity and the moisture levels ranged from 26 to $36 \%$. The soil saturation and moisture levels were consistent with the silty clay texture of the field area. The salinity levels surpassed the 
salt tolerance threshold of $1.6 \mathrm{dS} \mathrm{m}^{-1}$ for grape (Hanson et al., 2006), thereby, suggesting potentially adverse impact on grape production. As compared to other crops, grapevine was classified by Maas and Hoffman (1977) as moderately sensitive to salinity with a threshold soil saturation paste electrical conductivity of $1.5 \mathrm{dS} \mathrm{m}^{-1}$, beyond which there could be an estimated $9.6 \%$ yield reduction for every $1 \mathrm{dS} \mathrm{m}^{-1}$ increase in salinity. Depending on the grape varieties and corresponding salt exclusion capacity, the yield threshold salinity levels have been reported to range from 1.8 to $3.8 \mathrm{dS} \mathrm{m}^{-1}$. Based on 5-year or longer field trials with saline irrigation water $\left(0.4\right.$ to $\left.3.5 \mathrm{dS} \mathrm{m}^{-1}\right)$, several researchers concluded that for every $1 \mathrm{dS} \mathrm{m}^{-1}$ spike in salinity above the threshold levels, the yield would decrease by a range from 6 to $15 \%$ (Prior et al., 1992a; Walker et al., $2002 \&$ 2014).

Table 1. Summary statistics of soil analytical data

\begin{tabular}{lcccccc}
\hline Parameter & Unit & M & SD & LL & UL & CV \\
\hline Conductivity & $\mathrm{dS} \mathrm{m}^{-1}$ & 3.6 & 1 & 1.6 & 5.7 & 31 \\
Saturation & $\%$ & 39 & 6 & 27 & 48 & 16 \\
Moisture & $\%$ & 30 & 3 & 26 & 36 & 10 \\
Salinity & $\mathrm{dS} \mathrm{m}^{-1}$ & 3.7 & 0.4 & 2.8 & 4.8 & 10 \\
\hline
\end{tabular}

The limits were within $95 \%$ confidence interval. $\mathrm{M}=$ mean, $\mathrm{SD}=$ standard deviation, $\mathrm{LL}=$ lower limit, $\mathrm{UL}=$ upper limit, $\mathrm{CV}=$ coefficient of variation.

Figure 1 describes the spatial structural variance of soil salinity in the grape field for short and long lag distances and the inset table presents the characteristics of the variogram. The salt heterogeneity was best described by the Gaussian model that was characterized by a strong correlation $\left(\mathrm{r}^{2}=0.996\right)$ between the experimental and modeled data and a very low residual sum of squares value $(\mathrm{RSS}=0.0003)$. The semivariance was low due to the small variability exhibited by the salinity data. The model indicated that the salinity data were spatially dependent across most of the surveyed area and extended to the range value of $1008 \mathrm{~m}$. At this lag distance $\left(\mathrm{A}_{0}=1008 \mathrm{~m}\right)$, the variogram reached the sill variance of 1.91 and the autocorrelation started approaching zero beyond the range value. The sill value of the semivariance was the stabilization amplitude when the variogram started to level off. The overall heterogeneity had about $99 \%$ structural variance extending up to an effective range of $1746 \mathrm{~m}$. Minute nugget effect $\left(C_{0}=0.014\right)$ was observed that represented the random and intrinsic variability within the salt heterogeneity and could be attributed to measurement error, or short scale variability at distances smaller than the sample spacing. The Gaussian curve exhibited a typical parabolic pattern at the origin followed by a smooth variation with distance. The semivariograms were also analyzed and compared using variable lag intervals and lag distances and there were no substantial variations in the patterns of the local effect and nugget effect. The grape field exhibited high salinity and distinct lattices of salt heterogeneity albeit with a low variability. Overall, the spatial characteristics of salinity distributions were consistent with diverse solute dispersion that plausibly resulted from the prevailing water management practices. It should be noted that the spatial correlation structure was isotropic in nature and the semivariance computations relied on the magnitude of the lag distance vector, irrespective of the directions, and subsequently resulted in an omnidirectional Gaussian variogram. The concepts of variogram models were detailed by Isaaks \& Srivastava (1989). Applications of Gaussian semivariogram and kriging analyses have been reported for cotton field (Cetin \& Kirda, 2003) and desert ecosystem (Derakhshan et al., 2013) to describe spatial and temporal changes in soil salinity. Abiotic deleterious effects of water stress and salinity on grape composition have been discussed by Mirás-Avalos and Intrigliolo (2017).

Spatial heterogeneity of salt distributions across the root zone of the grape field is presented in Figure 2. The salinity levels generally remained between 2.8 and $4.6 \mathrm{dS} \mathrm{m}^{-1}$ with consistent variability $(10 \% \mathrm{CV})$ across the field. The 3.5-4 dS m${ }^{-1}$ level represented one of the most abundant salt concentrations across the surveyed area. At salinity levels above as well below this optimal range of abundance, the affected areas of salt buildup were relatively less broad. Thus, the yellow and orange layers, representing the higher salt concentrations, as well as the light blue layers corresponding to the lower salt buildup zones were characterized by narrow band width in the spatial map. There was an increasing pattern of salt accumulation from the northeastern corner of the field to the southwestern end that could also be attributed to the row effects along the north-south transects. Physiologically, grape shows decreasing photosynthesis rate with increasing salinity. This response is attributed to reduced aperture of stomata and greater resistance to carbon dioxide diffusion. Permanent cell damage may occur when lamina concentrations exceed $150 \mathrm{mM}$ chloride in the tissue water (Downton et al., 1990; Walker et al., 1997). Salinity can affect various growth parameters including timing of budburst, timing of veraison, bunch number, fruitfulness and cane number, and fruit size and sugar content (Downton et al., 1990; Prior et al., 1992a \& 1992b; Walker et 
al., 2002). In a grape field with salinity levels reaching up to $3.5 \mathrm{dS} \mathrm{m}^{-1}$, Prior et al. (1992b) observed significant reductions in bunch and cane numbers, bunches per node and cane, and fruitful shoots and nodes. Degaris et al. (2017) observed that under excessive saline condition, exogenous application of abscisic acid to grapevine root systems reduced chloride transport to the shoots. Presence of salts led to decrease in stomatal conductance, assimilation and transpiration, and the abscisic acid reduced chloride concentrations in all vine structures except the roots. Elevated salinity and drought conditions may trigger spike in abscisic acid concentrations within grapevines, which can subsequently reduce the ionic flux from roots to shoots.
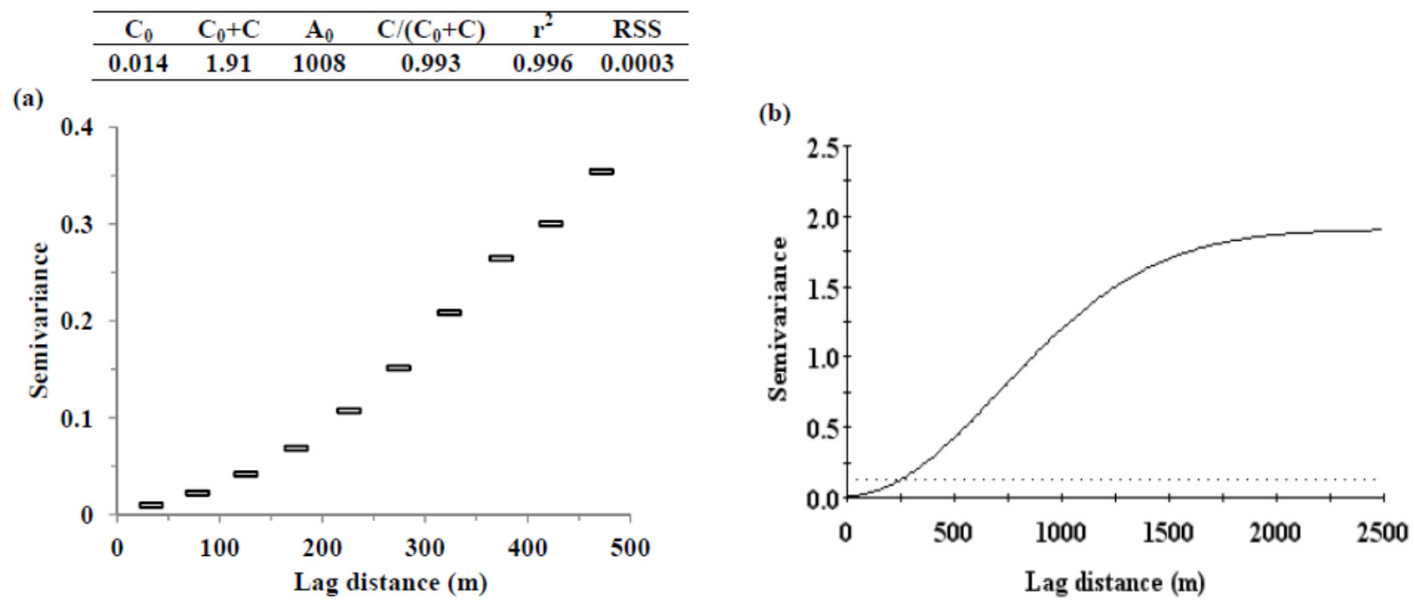

Figure 1. Gaussian semivariogram and spatial structure of salt heterogeneity in the grape field: (a) short and (b) long lag distances (Inset Table: $\mathrm{C}_{0}=$ nugget, $\mathrm{C}_{0}+\mathrm{C}=$ sill, $\mathrm{A}_{0}=$ range $(\mathrm{m}), \mathrm{C} /\left(\mathrm{C}_{0}+\mathrm{C}\right)=$ proportion, $\mathrm{r}=$ correlation coefficient, $\mathrm{RSS}=$ residual sum of squares)

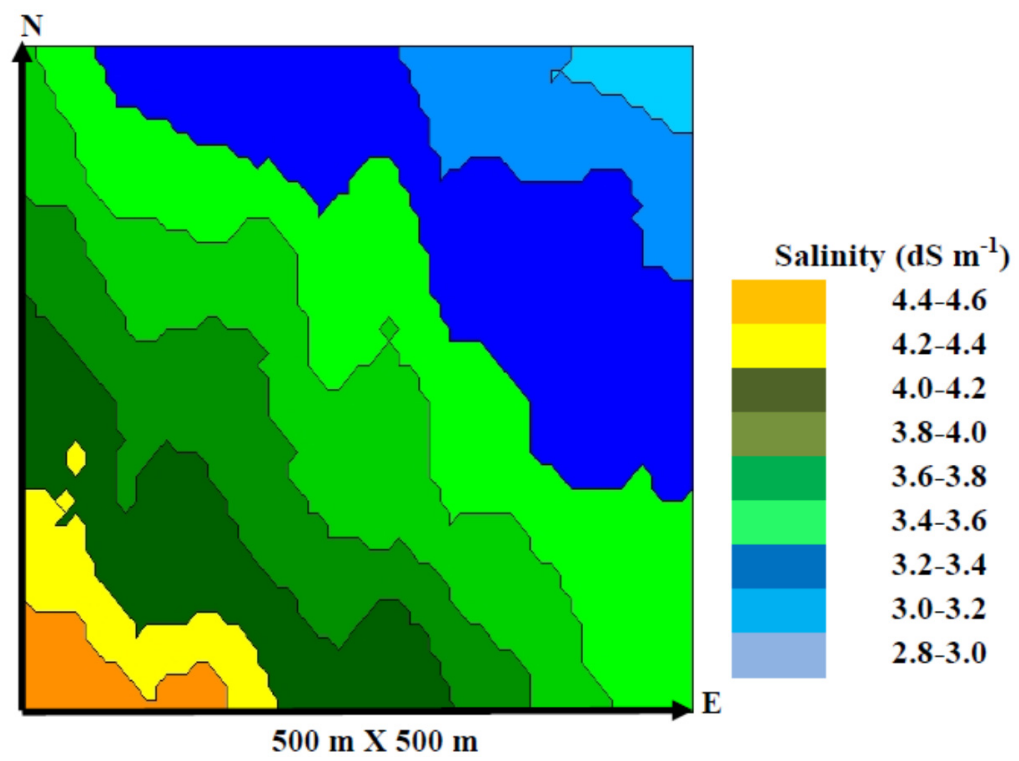

Figure 2. Spatial map of salt heterogeneity in the grape field

Figure 3 summarizes general salinity distribution across the grape field. The results showed that $98 \%$ of the salinity data were below $4.5 \mathrm{dS} \mathrm{m}^{-1}$. The majority of the salinity $(78 \%)$ remained in the $3-4 \mathrm{dS} \mathrm{m}^{-1}$ range, within which the 3-3.5 and 3.5-4 $\mathrm{dS} \mathrm{m}^{-1}$ sub-intervals were almost evenly distributed with corresponding values of 37 and $41 \%$, respectively. Around $19 \%$ of the surveyed points were characterized by $4-4.5 \mathrm{dS} \mathrm{m}^{-1}$ salinity and $2 \%$ data surpassed $4.5 \mathrm{dS} \mathrm{m}^{-1}$. Salinity level of $3 \mathrm{dS} \mathrm{m}^{-1}$ or less was observed in only $1 \%$ of the survey locations. It 
was noteworthy that both the upper and lower limits of salinity were distributed in a small percentage of the data $(<2 \%)$. Nevertheless, all observed values exceeded the salt tolerance threshold $\left(1.6 \mathrm{dS} \mathrm{m}^{-1}\right)$ for grape, thereby indicating the need for salinity management. Salinity tolerance for grapevine is dependent on the rootstock vigor and the salt exclusion capacity to restrict uptake of the dissolved ions and their transport from root to shoot (Tregeagle et al., 2010; Walker et al., $2002 \&$ 2014). The authors stated that grape yield and rootstock vigor have positively linear relationships under both non-saline and saline conditions. However, rootstocks with poor salt exclusion capacity can accumulate considerable amount of sodium and chloride ions over time resulting in substantial cell damage, severe growth and yield reductions and subsequent plant death. The chloride exclusion can be associated with the rootstock as well as the scion. In a 14-year long study, Walker et al. (2014) compared the effect of rootstocks on the salinity tolerance and ion exclusion capacity of two grape varieties irrigated with saline water of 1.65-2.10 dS m $\mathrm{d}^{-1}$ electrical conductivity. The authors observed that yield was positively correlated with rootstock-conferred vigor based on scion pruning mass measurement. The yield and the pruning mass were not correlated with sodium and chloride concentrations in the grape juice.

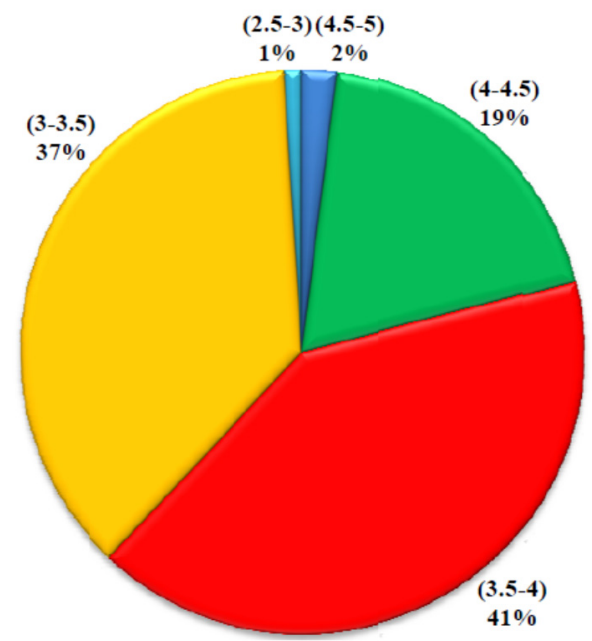

Figure 3. Percent distribution of soil salinity $\left(\mathrm{dS} \mathrm{m}^{-1}\right)$ across the grape field

\section{Conclusion}

Under continuous global climate changes, it is necessary that root zone salinity be rigorously monitored and maintained below the threshold values for grape with due attention to irrigation water and soil type management. The paucity of available irrigation water and escalation in soil salinization continue to affect grape yields and composition worldwide, and these stress-factors may eventually endanger profitable sustainability of viticulture. Our study presented the spatial structure of salinity distributions in a grape field from central California. The research provided important information on the levels, spatial distribution and variability of salinity using the electromagnetic sensing technique, stochastic methods and geostatistical analyses. The average root zone salt heterogeneity was accurately $\left(\mathrm{r}^{2}=0.996, \mathrm{RSS}=0.0003\right)$ described by the Gaussian model. Efficient water management can lead to lowering of irrigation volume. However, within the root zone, prolonged decrease in water application can result in salt buildup that gets further augmented by high salinity of the irrigation water. The recent drought in California has further exacerbated the salinization process due to reduction in water availability and salt movement across the root zone. Substantial amount of salt can accumulate in the root zone within just one growing season and the salinity may exceed the threshold salinity of grapes prior to completing the harvest period. Our study area exhibited low variability in salinity that was characterized by elevated levels higher than the salt tolerance threshold for grape, thereby, indicating the necessity for adaptive land and water management. Similar site-specific geospatial investigations can be universally applied for agricultural decision making as crop, soil and water resources management tools.

\section{References}

Cetin, M., \& Kirda, C. (2003). Spatial and temporal changes of soil salinity in a cotton field irrigated with lowquality water. Journal of Hydrology, 272, 238-249.

CDFA. (2017). California agricultural statistics review 2016-17. California Department of Food and Agriculture. 
Cal EPA. (2006). Salinity in the Central Valley-an overview. California: Regional Water Quality Control Board, Central Valley Region, California Environmental Protection Agency.

Cassel, F., Goorahoo, G., \& Sharmasarkar, S. (2015). Salinization and yield potential of a salt-laden Californian soil: an in situ geophysical analysis. Water Air Soil Pollution, 226, 422. https://doi.org/10.1007/s11270 -0152682-1

Cassel, F. (2017). Slingram prediction of optimal vegetable yields in drought-affected alkaline soil. Water Air Soil Pollution, 228, 186. https://doi.org/10.1007/s11270-017-3369-6

Cook, P. G., Walker, G. R., Buselli, G., Potts, I., \& Dodds, A. R. (1992). The application of electromagnetic techniques to groundwater recharge investigations. Journal of Hydrology, 130, 201-229.

Dane, J., \& Topp, C. (2002). Methods of soil analysis, physical methods. Wisconsin: Soil Science Society of America.

Degaris, K., Walker, R., Loveys, B., \& Tyerman, S. (2017). Exogenous application of abscisic acid to root systems of grapevines with or without salinity influences water relations and ion allocation. Australian Journal of Grape and Wine Research, 23, 66-76. https://doi.org/10.1111/ajgw.12264

Derakhshan, K., Amin, W., Salahedin, M., \& Hoshang, R. (2013). Spatial and temporal changes in soil salinity with geostatistics: a case study in Urmia Plain. International Journal of Agriculture and Crop Sciences, 5(3), 285-291.

Downton, W. J. S., Loveys, B. R., \& Grant, W. J. R. (1990). Salinity effects on the stomatal behavior of grapevine. New Phytologist, 116, 499-503.

Gavlak, R. G., Horneck, D. A., Miller, R. O., \& Kotuby-Amacher, J. (2003). Soil, plant, and water reference methods for the Western Region. Fort Collins, CO: A Western Regional Extension Publication.

Hanson, B., Grattan, S., \& Fulton, A. (2006). Agricultural salinity and drainage. California: Division of Agriculture and Natural Resources Publication 3375, University of California, Davis.

Isaaks, E. H., \& Srivastava, R. M. (1989). An introduction to applied geostatistics. Oxford University Press, New York.

Lesch, S. M., Rhoades, J. D., \& Corwin, D. L. (2000). ESAP-95 Version 2.01R: User manual and tutorial guide. Research Report 146. California: USDA-ARS George E. Brown, Jr. Salinity Laboratory.

Maas, E. V., \& Hoffman, G. J. (1977). Crop salt tolerance-current assessment. Journal of Irrigation and Drainage, 103, 115-134.

Martinez-Beltran, J., \& Manzur, C. L. (2005). Overview of salinity problems in the world and FAO strategies to address the problem. California: Proceedings of the international salinity forum.

Metternicht, G. I., \& Zinck, J. A. (2003). Remote sensing of soil salinity: potential and constraints. Remote Sensing of the Environment, 85, 1-20.

Mirás-Avalos, J., \& Intrigliolo, D. (2017). Grape composition under abiotic constrains: water stress and salinity. Frontiers in Plant Sci., 8, 851. https://doi.org/10.3389/fpls.2017.00851

Paine, J. G., White, W. A., Gibeaut, J. C., Andrews, J. R., \& Waldinger, R. (2004). Exploring quantitative wetlands mapping using airborne lidar and electromagnetic sensing on Mustang Island, Texas. Proceedings, American Geophysical Union, abstract No. B41A-24.

Prior, L. D., Grieve, A. M., \& Cullis, B. R. (1992a). Sodium chloride and soil texture interactions in irrigated fieldgrown Sultana grapevines. 1. Yield and fruit quality. Australian Journal of Agricultural Research, 43, 10511066.

Prior, L. D., Grieve, A. M., \& Cullis, B. R. (1992b) Sodium chloride and soil texture interactions in irrigated fieldgrown Sultana grapevines. 2. Plant mineral content, growth and physiology. Australian Journal of Agricultural Research, 43, 1067-1083.

Robertson, G. P. (2000). GS+, GeoStatistics for the environmental sciences, version 5.1. Plainwell, MI: Gamma Design Software.

Tregeagle, J. M., Tisdall, J. M., Tester, M., \& Walker, R. R. (2010). $\mathrm{Cl}^{-}$uptake, transport and accumulation in grapevine rootstocks of differing capacity for $\mathrm{Cl}^{-}$exclusion. Functional Plant Biology, 37, 665-673. 
Walker, R. R., Blackmore, D. H., Clingeleffer, P. R., \& Iacono, F. (1997). Effect of salinity and Ramsey rootstock on ion concentrations and carbon dioxide assimilation in leaves of drip-irrigated, field-grown grapevines (Vitis vinifera L. cv. Sultana). Australian Journal of Grape and Wine Research, 3, 66-74.

Walker, R. R., Blackmore, D. H., Clingeleffer, P. R., Boutry, M., \& Duby, G. (2002). Rootstock effects on salt tolerance of irrigated field-grown grapevines (Vitis vinifera L. cv. Sultana). 1. Yield and vigour interrelationships. Aust. J. Grape Wine Res., 8, 3-14. https://doi.org/10.1111/j.1755-0238.2002.tb00206.x

Walker, R. R., Blackmore, D. H., Clingeleffer, P. R., \& Emanuelli, D. (2014). Rootstock type determines tolerance of Chardonnay and Shiraz to long-term saline irrigation. Aus. J. GrapeWine Res., 20, 496-506. https://doi.org/10.1111/ajgw.12094

USDA. (2006). Soil survey of Fresno County, California. Washington, DC: United States Department of Agriculture: Western Part.

USDA. (2014). Farm and ranch irrigation survey (Volume 3, part 1). United States Department of Agriculture.

Viberga, A., Berntssonb, A., \& Lidéna, K. (2013). Archaeological prospection of a high altitude Neolithic site in the Arctic mountain tundra region of northern Sweden. Journal of Archaeological Science, 40, $2579-2588$.

\section{Copyrights}

Copyright for this article is retained by the author(s), with first publication rights granted to the journal.

This is an open-access article distributed under the terms and conditions of the Creative Commons Attribution license (http://creativecommons.org/licenses/by/4.0/). 